\title{
THERMALLY ACTIVATED VISCOUS REMANENCE IN SOME MAGNETITE- AND HEMATITE-BEARING DOLOMITES
}

\author{
Mike Jackson and Rob Van der Voo \\ Department of Geological Sciences, the University of Michigan
}

\begin{abstract}
A Brunhes-age viscous remanent magnetization (VRM) carried by magnetite and hematite in the El Paso and Montoya dolomite formations has unblocking temperatures significantly higher than those predicted by single-domain theory. The samples appear to contain a substantial fraction of pseudo-single domain magnetite, suggesting transdomain processes may be responsible for the stable VRM. A strong inverse correlation between the occurrence of high unblocking temperatures and high isothermal remanence fractions acquired above 0.3 Tesla suggests that the hematite grain size may also be important in determining the range of observed temperatures. Larger grains are inferred to have lower coercivities but higher unblocking temperatures. An older, reverse-polarity component is also observed, and appears to be a record of late Cretaceous-Tertiary tectonic activity.
\end{abstract}

\section{Introduction}

Remagnetization of magnetite-bearing rocks is now recognized as a widespread and pervasive phenomenon, and much recent work has been carried out to improve our understanding of the mechanisms of remagnetization. Several authors have observed Ti-free magnetites in spheroidal and botryoidal forms, and inferred a diagenetic origin for them [McCabe et al., 1983; Wisniowiecki et al., 1983; Horton et al., 1984; Elmore et al., 1986; Kesler et al., 1986]. Kent [1985] has argued that thermoviscous processes must also inevitably play a role, and may produce very stable VRMs, particularly when elevated temperatures associated with orogeny and deep burial coincide with long intervals of constant polarity. Moon and Merrill [1986] suggest that transdomain processes in pseudo-single domain (PSD) or very small multidomain (MD) grains may provide the mechanism for high- stability VRM acquisition.

In order to assess the relative importance of the various potential mechanisms of remagnetization, it is essential to combine paleomagnetic and rock-magnetic observations. In this paper we document the occurrence of a high-stability Cenozoic remanence in the Ordovician El Paso and Montoya carbonate formations from the Sacramento Mountains of New Mexico, and we report results of several rockmagnetic experiments. We then discuss the implications of these observations for the mechanism of remagnetization in these rocks.

\section{Geologic Setting}

The Sacramento Mountains are a fault- block range at the eastern edge of the Basin and Range Province

Copyright 1986 by the American Geophysical Union.

Paper number 6L6381

0094-8276/86/006L-6381\$03.00 in south-central New Mexico. The geology of the Sacramento Mountains has been summarized by Pray [1961]. Paleozoic strata were folded and faulted in the Late Pennsylvanian-Early Permian and again in Late Cretaceous-Early Tertiary time. Andesitic intrusives were emplaced at about $30 \mathrm{Ma}$, concurrent with the onset of crustal extension to the west. Major uplift of the range probably began in late Tertiary time and has continued into recent times, with an offset along the boundary fault of more than $2000 \mathrm{~m}$. The $\mathrm{El}$ Paso formation is lower Ordovician, and the Montoya is middle Ordovician. Both the El Paso and the Montoya formations are dolomitic, and the Montoya contains abundant coarse sandy material.

\section{Paleomagnetic and Rockmagnetic Analysis}

Figure 1 shows the typical response of the samples to stepwise thermal demagnetization treatments. A bivectorial decay of the remanence was apparent in almost every case. A northerly and steeply downward component was removed first, followed by a southerly or southeasterly and upward component. The lowertemperature component is generally quite close to the Earth's axial dipole field direction, and the lowest unblocking temperature fraction $\left(T_{u b} \leq 180^{\circ} \mathrm{C}\right)$ is commonly deflected towards the east, that is, towards the actual present-day field (PDF) direction (declination $D=13^{\circ}$ ). Thermal demagnetization is much more effective than alternating-field (AF) treatments at separating the two components. These observations strongly suggest a thermally- activated viscous origin for the northerly component.

The $T_{u b}$ spectra for the two components exhibit a clear overlap over the range $300^{\circ}$ to $380^{\circ} \mathrm{C}$ (Fig. 1a). Inspection of stereoplots of the data (Fig. 1b) shows that the overlap is actually much larger and that the $T_{u b}$ spectrum of the PDF component extends up to at least $450^{\circ} \mathrm{C}$, since the data continue to move along a great-circle trajectory. This suggests that there may be two carriers for the northerly component, with different $T_{u b}$ spectra: one with high intensities, extending up to $300^{\circ}$ to $350^{\circ}$, and one with lower intensities ranging up to $450^{\circ} \mathrm{C}$.

Site mean directions for the two components were computed by the method of Bailey and Halls [1984] and are shown in Figure 1c. The northerly component is tightly grouped and clearly fails the fold test. The southerly component is distributed along a great-circle arc, indicating again its composite nature. The very good fit to a great circle prior to tilt correction argues that both components are younger than the deformation. Position along the great circle reflects the degree 
JNM 22

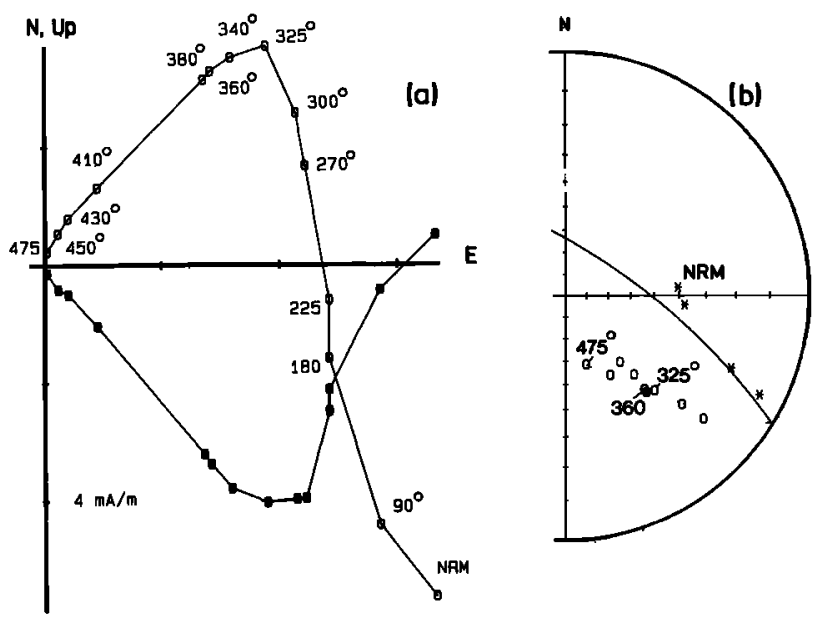

Site Means

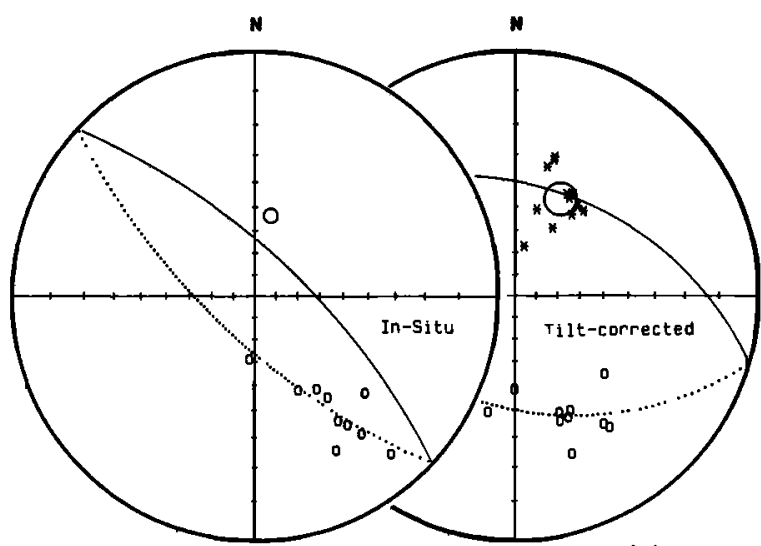

(c)

Fig. 1. Typical bivectorial decay during thermal demagnetization. (a) Orthogonal vector diagram, in-situ coordinates. Solid symbols are projections on the horizontal (N, E) plane, open symbols on the vertical (Up, E). (b) Equal angle plot of the same data. Asterisks are projections on the lower hemisphere, circles on the upper. (c) Site mean directions for the normal and reversed components. Circle of $95 \%$ confidence is shown for the normal component, which clearly postdates folding; individual in-situ directions are not shown, for clarity. The reversed component site means are distributed along a great circle, indicating variable contamination by the normal component.

of contamination by the PDF component, shallower directions indicating greater contamination.

Acquisition of isothermal remanent magnetization (IRM) shows that the dominant remanence carrier is magnetite but that variable amounts of hematite are also present in the rocks (Fig. 2a). The positive slopes at fields above $0.3 \mathrm{~T}$ indicate the presence of a highcoercivity mineral [Dunlop, 1972], and the alternatingfield (AF) and thermal demagnetization characteristics rule out goethite [Lowrie and Heller, 1981]. We therefore suggest that the normal polarity VRM is carried by magnetite with $T_{u b}$ 's up to about $325^{\circ}$, and hematite with $T_{u b}$ 's up to $450^{\circ}$. Magnetite with $T_{u b}$ 's from about $350^{\circ}$ to $450^{\circ} \mathrm{C}$ carries the reverse polarity component.
Modified Lowrie-Fuller tests [Johnson et al., 1975] distinguish two groups of sites. One group has clear single domain signatures. The other group has decay curves for which the strong- and weak-field remanences coincide, which may indicate a bimodal size distribution, or a predominance of PSD grains [Dunlop, 1983b]. Initial/anhysteretic susceptibility ratios were measured for several samples from the sites with the lowest hematite content, and these indicate apparent magnetite grain sizes near $1 \mu \mathrm{m}$ [Banerjee et al, 1981; King et al., 1982]. We conclude that the samples probably contain an appreciable magnetite fraction with grain sizes in the range proposed by Moon and Merrill [1986] for transdomain VRM.

Site-mean inclinations exhibit a strong covariance with IRM characteristics. Figure $2 b$ compares site-mean inclinations for the southerly component of Fig. 1c (in situ) with the fraction of total IRM acquired above 0.3 $\mathrm{T}$, which can be considered a qualitative measure of the relative abundance of hematite [e. g., Butler, 1982]. Oddly, it shows a trend precisely opposite to what one would expect: more high-coercivity material corresponds to steeper inclinations and less contamination. We discuss this further below.
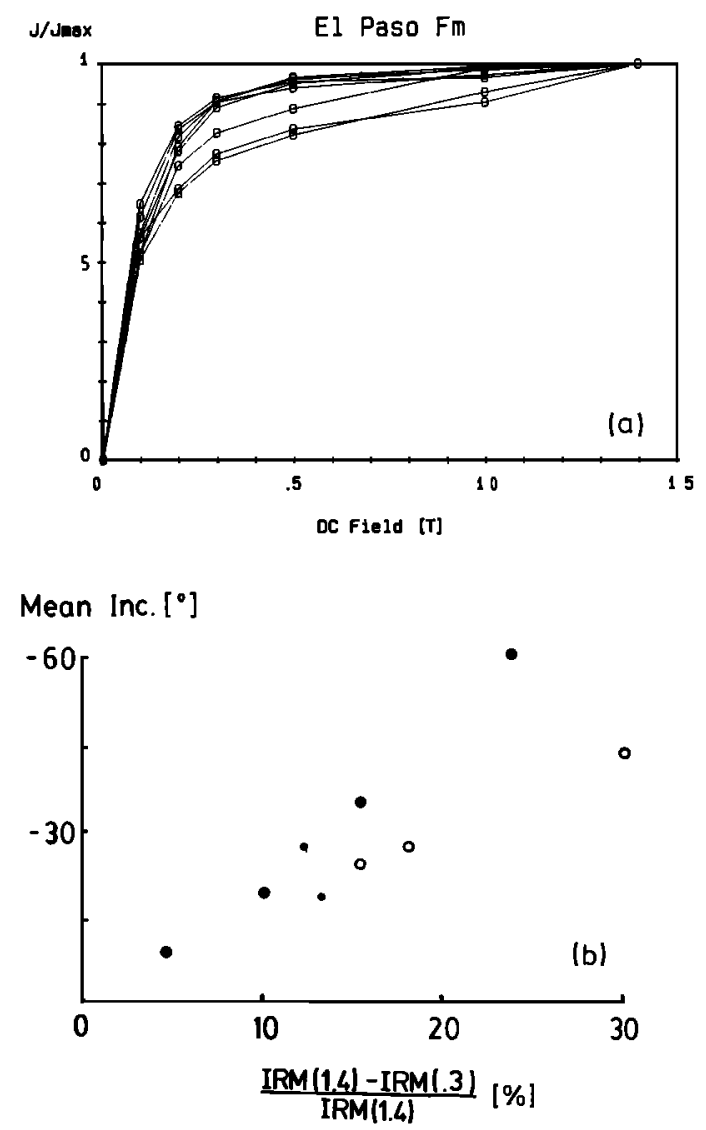

Fig. 2. (a) IRM acquisition curves indicate magnetite as the dominant remanence carrier, with up to $30 \%$ of the IRM residing in hematite. (b) A strong correlation between in-situ site-mean inclination and fraction of total IRM acquired above $0.3 \mathrm{~T}$. Closed symbols are El Paso sites, open symbols are Montoya. The two small symbols are the outliers from the great-circle distribution of Fig. 1c. 


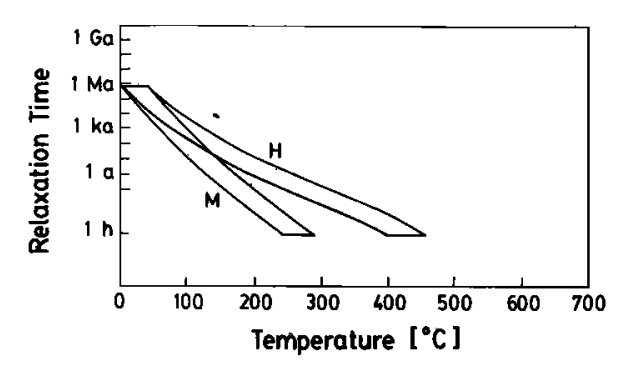

Fig. 3. Predicted unblocking temperatures for a Brunhes-age thermoviscous remanence from eq. (3), after Walton [1980], are in virtually perfect agreement with our observations.

\section{Discussion}

Thermal activation of magnetic remanence has been studied extensively from a theoretical standpoint [e. g., Dunlop, 1973; Pullaiah et al., 1975; Walton, 1980]. Néel theory states that an assemblage of magnetic particles approaches equilibrium with an external field as $\exp (-t / \tau)$, where $\tau$, the relaxation time, is given by:

$$
\left(\tau^{-1}\right)=C \exp \left(\epsilon_{0} / k T\right)
$$

In this equation $\epsilon_{0}$ is the energy barrier to moment reversal within a particle and the frequency factor $\mathrm{C}$ is equal to about $10^{10}$. For magnetite with shape anisotropy, $\epsilon_{0}$ is related to grain geometry and proportional to volume and $J_{s}^{2}$ (where $J_{s}$ is the saturation magnetization). For an assemblage of identical SD grains, Pullaiah et al. [1975] derive the relation:

$$
\frac{\ln \left(C t_{1}\right)}{\ln \left(C t_{2}\right)}=\frac{T_{2} J_{s}^{2}\left(T_{1}\right)}{T_{1} J_{s}^{2}\left(T_{2}\right)}
$$

which describes the time- temperature conditions $\left(t_{2}, T_{2}\right)$ that will remove a magnetization acquired at $\left(t_{1}, T_{1}\right)$. Walton [1980] considers the effects of different distributions of grain sizes and anisotropies and proposes the relation should instead be:

$$
\left[\frac{\ln \left(C t_{1}\right)}{\ln \left(C t_{2}\right)}\right]^{3+r}=\left[\frac{T_{2} J_{s}^{2}\left(T_{1}\right)}{T_{1} J_{s}^{2}\left(T_{2}\right)}\right]^{2+r}
$$

which is more strongly time- dependent than (2). Middleton and Schmidt [1982] have plotted (3) for $r=-1$, approximating a log-normal grainsize distribution.

Figure 3 shows predicted $T_{u b}$ 's for a Bruhnes-age thermoviscous remanence using Walton's relation (eq, 3). Magnetite $T_{u b}$ 's of up to $300^{\circ}$ and hematite $T_{u b}$ 's of up to $450^{\circ} \mathrm{C}$ are in virtually perfect agreement with our observed values. Even if the northerly component was acquired at elevated temperatures at depth, magnetite $T_{u b}$ 's from (2) do not exceed $250^{\circ}$ unless implausibly high burial temperatures of more than $150^{\circ} \mathrm{C}$ are invoked. Kent [1985] has observed $T_{u b^{\prime}}$ 's of up to $275^{\circ}$ $\mathrm{C}$ for a viscous remanence in limestone cobbles from a 10 ka glacial deposit, which are close to the values predicted by (3) and more than $100^{\circ} \mathrm{C}$ higher than those from (2). Our results and those of Kent [1985] indicate that thermal activation processes are more potent than equation (2) allows, and that equation (3) may be a fairly accurate predictor of $T_{u b}$, at least in some cases.
Kent [1985] suggests that elevated $T_{u b}$ 's may reflect the importance of multidomain wall activation processes, as proposed by Dunlop [1983]. Where such processes are important, equation (2) gives a minimum value for $T_{u b}$, and a broad tail may extend to much higher temperatures. Moon and Merrill [1986] suggest that the stability of transdomain VRM may exceed that of the primary magnetization, but a quantitative $\mathrm{t}-\mathrm{T}$ relationship has not yet been developed. In this study, we infer that a significant PSD fraction is probably present in most of the samples and that it may be the carrier of the stable VRM.

The fact that equation (3) fairly accurately predicts $T_{u b}$ 's in these cases is fortuitous, as pointed out by Dunlop [1986], because that is not what (3) is actually supposed to do. Equation (2) was derived by setting the non-temperature- dependent part of the activation energy (grain shape and volume) to a constant value. It therefore relates different $(t, T)$ that will activate the same grains. The derivation of equation (3), on the other hand, involves taking a constant value for the total moment of a population with distributed volumes and anisotropies. Equation (3) thus relates the various $(t, T)$ which will produce the same total moment, but not necessarily in the same grains. For predicting $T_{u b}$ 's then, equation (2) incorporates the appropriate condition. Further, although (2) is nominally for SD grains, it should not be greatly different for domain wall displacements in MD grains. Nevertheless our new results, in conjunction with those of Kent [1985], suggest that equation (3) is a good empirical predictor of $T_{u b}$ in certain cases, perhaps those where transdomain processes are important.

The inverse correlation between high- coercivity IRM and contamination of the southerly component is difficult to explain but too strong to ignore. One possible explanation is that the size distribution of the hematite is important. Dankers [1978] shows that the fraction of IRM acquired above $0.3 \mathrm{~T}$ varies by as much as $30 \%$ for hematite samples of various grain sizes, with higher fractions for finer grains. The blocking relation of Pullaiah et al. [1975] predicts a $T_{u b}$ of about $350^{\circ} \mathrm{C}$ for a Brunhes-age VRM in hematite. With increasing grain sizes a higher $T_{u b}$ tail may begin to develop, extending up to $450^{\circ}$ as we have observed, and thus overlapping with the southerly component.

The age and origin of the southerly component are difficult to constrain. Because the great circle trajectories of the demagnetization data are all more or less parallel, the intersection is very poorly defined and it is geometrically not possible to find the true remanence direction directly from the data. However, we can make an indirect estimate using expected directions computed from the apparent polar wander path for North America [Van der Voo, 1987]. These directions intersect the great circle defined by the site means at about $D / I=$ 165 / - 65, and give a corresponding age of 65 to $75 \mathrm{Ma}$. If this is correct, then the southerly component is not related to the $30 \mathrm{Ma}$ intrusive activity, but is a record of the Cretaceous- Tertiary tectonic activity. In view of this, and the obvious lack of correlation with the Cretaceous normal polarity interval, the southerly component may be dominantly a CRM. 


\section{Conclusions}

The northerly downward component of magnetization we observe in the El Paso and Montoya formations is dominantly of thermoviscous origin, but exhibits $T_{u b}$ 's significantly higher than those predicted by singledomain theory for magnetite and hematite. Magnetite with $T_{u b}$ 's up to $350^{\circ} \mathrm{C}$ and hematite with $T_{u b}$ 's to $450^{\circ}$ $\mathrm{C}$ carry a Brunhes-age remanence, perhaps a transdomain VRM. Although we cannot rule out a CRM contribution to the high $T_{u b}$ tail, this would not explain the observed inverse correlation of high $T_{u b}$ 's with the presence of high-coercivity IRM carriers. The most parsimonious explanation of this observation involves a grain size effect in hematite. The older, reverse polarity component is probably a CRM residing dominantly in magnetite, and related to late Cretaceous-Tertiary tectonism.

Acknowledgements. We thank E. Leach for assistance in the field, H. Gourley for assistance in the lab, and R. J. E. Johnson for discussion of various aspects of this study. Comments from D. T. A. Symons improved the manuscript. Financial support for field work came from the GSA and Sigma Xi. Lab work was funded by NSF (EAR84-07007 to R. Van der Voo). M. Jackson received additional support from an NSF graduate fellowship and a Horace $H$. Rackham graduate fellowship during the course of this study.

\section{References}

Bailey, R. C., and H. C. Halls, Estimate of confidence in paleomagnetic directions derived from mixed remagnetization circle and direct observational data, $J$. Geophys., 54, 174-182, 1984.

Banerjee, S. K., J. King, and J. Marvin, A rapid method for magnetic granulometry with applications to environmental studies, Geophys. Res. Lett., 8, 333-336, 1981.

Butler, R. F., Magnetic mineralogy of continental deposits, San Juan basin, New Mexico, and Clark's Fork basin, Wyoming, J. Geophys. Res., 87, 7843-7852, 1982.

Dankers, P., Magnetic properties of dispersed natural iron-oxides of known grain- size, $\mathrm{Ph}$.D. dissertation, State University of Utrecht, 142 p., 1978.

Dunlop, D. J., Magnetic mineralogy of unheated and heated red sediments by coercivity spectrum analysis, Geophys. J. R. astr. Soc., 27, 37-55, 1972.

Dunlop, D. J., Theory of the magnetic viscosity of lunar and terrestrial rocks, Rev. Geophys. Space Phys., 11, 855-902, 1973.

Dunlop, D. J., Viscous magnetization of 0.04-100 $\mu \mathrm{m}$ magnetites, Geophys. J. R. astr. Soc., 74, 667-687, 1983a.

Dunlop, D. J., Determination of domain structure in igneous rocks by alternating field and other methods, Earth Planet. Sci. Lett., 63, 353-367, 1983 b.

Dunlop, D. J., Polarity bias in remagnetization?, EOS, $67,269,1986$.

Elmore, R. D., K. A. Cochran, and K. E. Nick, Authigenic magnetite and hydrocarbon migration: testing the hypothesis in the lower Ordovician Arbuckle Group, southern Oklahoma, EOS, 67, 265, 1986.

Horton, R. A., J. W. Geissman, and R. J. Tschauder, Paleomagnetism and rock magnetism of the Mississip- pian Leadville (carbonate) formation and implications for the age of sub-regional dolomitization, Geophys. Res. Lett., 11, 649-652, 1984.

Johnson, H. P., W. Lowrie, and D. V. Kent, Stability of anhysteretic remanent magnetization in fine and coarse magnetite and maghemite particles, Geophys. J. R. astr. Soc., 41, 1-10, 1975.

Kent, D. V., Thermoviscous remagnetization in some Appalachian limestones, Geophys. Res. Lett., 12, 805808, 1985.

Kesler, S. E., V. Bachtadse, R. Van der Voo, and E. R. Graber, New paleomagnetic results from lower Ordovician carbonates, eastern Tennessee, EOS, 67, 270, 1986.

King, J., S. K. Banerjee, J. Marvin, and Ö. Özdemir, A comparison of different methods for determining the relative grain size of magnetite in natural sediments: Some results from lake sediments, Earth Planet. Sci. Lett., 59, 404-419, 1982.

Lowrie and Heller, Magnetic properties of marine limestones, Rev. Geophys. Space Phys., 20, 171-192, 1982.

McCabe, C., R. Van der Voo, D. R. Peacor, C. R. Scotese, and R. Freeman, Diagenetic magnetite carries ancient yet secondary remanence in some Paleozoic sedimentary carbonates, Geology, 11, 221-223, 1983.

Middleton, M. F., and P. W. Schmidt, Paleothermometry of the Sidney basin, J. Geophys. Res., 87, 53515359, 1982.

Moon, T. and R. T. Merrill, A new machanism for stable viscous remanent magnetization and overprinting during long magnetic polarity intervals, Geophys. Res. Lett., 13, 737-740, 1986.

Pray, L. C., Geology of the Sacramento Mountains Escarpment, Otero County, New Mexico, N. Mex. Bureau Mines Bull, 35, 144 p., 1961.

Pullaiah, G., E. Irving, K. L. Buchan, and D. J. Dunlop, Magnetization changes caused by burial and uplift, Earth Planet. Sci. Lett., 28, 133-143, 1975.

Van der Voo, R., Paleomagnetism of continental North America: The craton, its margins, and the Appalachian belt, in: Geophysical Framework of the Continental United States, L. C. Pakiser and W. D. Mooney, eds, Geol. Soc. Am. Mem., in press, 1987.

Walton, D., Time-temperature relations in the magnetization of assemblies of single domain grains, Nature, 286, 245-247, 1980.

Wisniowiecki, M. J., R. Van der Voo, C. McCabe, and W. C. Kelly, A Pennsylvanian paleomagnetic pole from the mineralized late Cambrian Bonneterre formation, southeast Missouri, J. Geophys. Res., 88, 6540-6548, 1983.

York, D., A formula describing both magnetic and isotopic blocking temperatures, Earth Planet. Sci. Lett., 39, 89-93, 1978.

Mike Jackson and Rob Van der Voo, Department of Geological Sciences, The University of Michigan, Ann Arbor, MI 48109-1063.

(Received September 19, 1986;

Accepted October 20, 1986.) 